\title{
Nasal Tuberculosis Mimicking Fungal Disease: A Rare Case Report
}

\author{
Ramandeep Singh Virk, Darwin Kaushal, Ravi Sankar, Amit Babel
}

\begin{abstract}
Tuberculosis (TB) is a global health problem with 8 million people infected annually and 3 million people dying from diseases related to its complications. ${ }^{1,2}$ Tuberculosis chiefly affects the pulmonary system but it can also involve extrapulmonary sites including the head and neck region. The aim of this case report was to evaluate the clinical characteristics of head and neck TB lesions and to report this rare site.
\end{abstract}

Keywords: Tuberculosis, Nasal, Fungal disease.

How to cite this article: Virk RS, Kaushal D, Sankar R, Babel A. Nasal Tuberculosis Mimicking Fungal Disease: A Rare Case Report. J Postgrad Med Edu Res 2013;47(4):218-220.

\section{Source of support: Nil}

Conflict of interest: None declared

\section{INTRODUCTION}

Head and neck tuberculosis is very rare, except for cervical adenitis. The third most common form of TB in head and neck is oropharynx, after adenopathies and laryngeal TB. ${ }^{3-5}$ After reviewing the English language literature, oral TB has been generally regarded as a very rare entity (effecting approximately 0.05 to $5.00 \%$ of patients with TB). ${ }^{1,6}$ This disease rarely fits in the differential diagnoses of head and neck lesions. We report a case of nasal TB which is very rare.

\section{CASE REPORT}

A 20-year-old male was referred to ear, nose and throat (ENT) outpatient department of Postgraduate Institute of Medical Edication and Research (PGIMER) with complaints of swelling over dorsum of nose since last 4 years, which was insidious in onset and gradually progressive. There was no history of trauma, pain, bleeding, nasal obstruction, nasal discharge, sneezing, watering or redness of eyes or any upper respiratory tract infection. There was no history of tuberculosis (TB), diabetes, hypertension, asthma in the past. Patient denied any addiction or history of drug allergy.

On nasal endoscopic examination, the septum, inferior turbinate and nasal mucosa appeared normal. Oral cavity examination was within normal limit. On gross inspection of the nose, there was a diffuse swelling over dorsum of nose measuring about $2 \times 2 \mathrm{~cm}$ and was superiorly extending from glabella to the tip of the nose inferiorly. Laterally, it was reaching till nasofacial groove. On palpation, swelling was firm, nontender, with normal temperature and without any visible pulsations.
Fine needle aspiration cytology from the swelling was consistent with TB.

VDRL, HIV, ANA c-ANCA and p-ANCA were negative. Chest X-ray revealed fibrosis of right upper lobe. Mantoux test was negative.

On neck examination, there was no lymphadenopathy. Laryngeal crepitus was present and there was no laryngeal widening. Oral examination and fiberoptic laryngoscopy were normal. The white cell count was within normal range. The sputum smear was also negative for acid-fast bacilli. Hemoglobin was $11 \mathrm{~g} / \mathrm{dl}$ and erythrocyte sedimentation rate (ESR) was $76 \mathrm{~mm} / \mathrm{h}$. Biopsy results were consistent with TB. The patient was transferred under internal medicine for commencement of ATT.

\section{Differential Diagnosis}

Phacomycosis, midline granulomas (i.e. Wegener's granulomatosis, leprosy, sarcoidosis, subcutaneous phycomycosis, granulomatous syphilis, etc.) or carcinomas, nasal TB.

\section{DISCUSSION}

Tuberculosis is caused by Mycobacterium tuberculosis, an acid-fast bacillus that is transmitted primarily through the respiratory tract. The incidence of TB in underdeveloped countries is increasing, and this is thought to be because of associated poor hygiene conditions and the greater prevalence of AIDS. ${ }^{7}$ Tuberculosis is often an unexpected finding in biopsy results because of nonspecific nature of its presentation. With the advances in the diagnosis of TB and with even more faster and more reliable tests, such as polymerase chain reaction (PCR), its detection almost always requires the performance of invasive procedures, such as fine needle aspiration or biopsies. The gold standard diagnostic tool is still the culture of mycobacteria which requires a waiting period of more than a month.

The greatest recent advance in TB treatment is the existence of a pharmacological cure, making surgery practically unnecessary following diagnosis.

The nose is resistant to invasion by acute TB of any part of the respiratory tract because of the structure of mucosa, respiratory movements of the cilia and bactericidal secretions. Nose can become infected either directly (primarily) through the air flow by people sneezing or coughing or by direct inoculation by finger borne infections and by instrumentation. It may become infected indirectly (secondarily) 
through the blood and lymph vessels. ${ }^{5}$ It is twice as common in females as in males and prevalent in persons living in unhygienic surroundings with poor health. ${ }^{6}$ The more frequent secondary form is due to autoinoculation from the sputum in patients with pulmonary TB. Clinical manifestations caused by TB in ENT are generally nonspecific. They can coexist with other TB locations. General physical examination must be carried out as well as a chest X-ray to rule out pulmonary involvement. If there is parenchymal pulmonary involvement, obtaining sputum samples for Ziehl-Neelsen staining may facilitate the diagnosis.

Tuberculous involvement of nasal cavity usually appears as a rapidly growing ulcer or tumor mass in the quadrangular cartilage of the nasal septum. Frequently, a septal perforation develops but in contrast to lupus vulgaris, the adjoining skin is not affected. The anterior portions of the inferior turbinate are frequently involved. Involvement of posterior nares is rare and nasal floor is almost always spared. ${ }^{2,7}$ Direct extension of infection from nose to ethmoid sinus may occur. The organism may spread into the sphenoid, frontal or maxillary sinuses through the sinus ducts. The orbit may be invaded and infection can extend to cranial cavity., ${ }^{3,8}$ In our case, the infection was localized to skin and subcutaneous tissues.

The clinical symptoms of nasal TB may not manifest themselves until the disease is well on its way. Bloody nasal discharge may be the earliest, possibly the only presenting symptom. Pain, nasal obstruction and dryness in the nose or throat are other common presentation. The eye symptoms may occur due to blockage of the nasolacrimal duct or direct orbital invasion. Headaches may occur with invasion of the sinuses and extension to cranial cavity. 5,7

Imaging tests can identify the implications of the local lesion caused by TB in different areas of ear, nose and throat. In lymphadenopathies ultrasonography, computerized tomography and magnetic resonance imaging can direct diagnosis toward TB by visualizing extension, formation of clusters, presence of central hypodensity of the lymph node, peripheral enhancement on administration of contrast and inflammation of the adjacent tissues. ${ }^{9-13}$

Tuberculosis is often an unexpected finding and suspected after carrying out a biopsy either with fine needle aspiration or incisional biopsy of a lesion with a ulcereted, swollen and/or tumorous appearance. In the histological study of TB lesions, the typical findings are the presence of granulomas with multinucleate giant cells, acute neutrophilic infiltration, with or without necrosis. Staining of histological samples with specific techniques, which should always be performed whenever granulomas are found, may detect bacilli resistant to acid-alcohol.

These bacteria are usually tuberculous mycobacteria. Confirmation of the diagnosis is through culture in specific media. This culture is also used to carry out the differential diagnosis with infections caused by other mycobacteria, which may have been detected in the histological study, and is used to detect drug resistance to antitubercular drugs. However, the cultivation of mycobacteria has a limited yield and is a slow technique that often takes weeks, so its results are generally received when the patient is already on treatment. Other faster techniques have been explored to help to avoid a biopsy, especially in the case of tuberculous adenopathies. The diagnostic performance of cytology obtained by fine needle aspiration of tuberculous adenopathies varies according to the series, with specificity of 93 to $100 \%,{ }^{14,15}$ with the presence of granulomas being the finding considered indicative of TB.

It is important to remember that in all patients with TB, infection by human immunodeficiency virus should be ruled out, especially if the TB is extrapulmonary and there is no apparent immunodeficiency. ${ }^{16}$

Tuberculosis of the nose till date remains a very rare entity and treatment remains medical.

\section{REFERENCES}

1. Phelan JA, Jimenez V, Tompkins DC. Tuberculosis. Dent Clin North Am 1996;40:327-341.

2. Yepes JF, Sullivan J, Pinto A. Tuberculosis: medical management update. Oral Surg Oral Med Oral Pathol Oral Radiol Endod 2004;98:267-273.

3. Fortun J, Sierra C, Raboso E, Pérez C, Plaza G, Navas E, et al. Tuberculosis del área otorrinolaringológica: formas laríngeas y extralaríngeas. Enferm Infecc Microbiol Clin 1996;14:352-356.

4. Sierra C, Fortun J, Barros C, Melcon E, Condes E, Cobo J, et al. Extra-laryngeal head and neck tuberculosis. Clin Microbiol Infect 2000;6:644-648.

5. Eng HL, Lu SY, Yang CH, Chen WJ. Oral tuberculosis. Oral Surg Oral Med Oral Pathol Oral Radiol Endod 1996;81:415-420.

6. Mignogna MD, Muzio LL, Favia G, Ruoppo E, Sammartino G, Zarrelli C, et al. Oral tuberculosis: a clinical evaluation of 42 cases. Oral Dis 2000;6:25-30.

7. Miziara ID. Tuberculosis affecting the oral cavity in Brazilian HIV-infected patients. Oral Surg Oral Med Oral Pathol Oral Radiol Endod 2005;100:179-182.

8. Hashimoto Y, Tanioka H. Primary tuberculosis of the tongue: report of a case. J Oral Maxillofacial Surg 1989;47:744-746.

9. Smith WHR, Davis D, Mason KD, Onions JP. Intraoral and pulmonary tuberculosis following dental manipulation. Lancet 1982;1:842-843.

10. Ying M, Ahuja AT, Evans R, King W, Metreweli C. Cervical lymphadenopathy: sonographic differentiation between tuberculous nodes and nodal metastases from non-head and neck carcinomas. J Clin Ultrasound 1998;26:383-389.

11. Reede DL, Bergeron RT. Cervical tuberculous adenitis: CT manifestations. Radiology 1985;154:701-704.

12. King AD, Ahuja AT, Metreweli C. MRI of tuberculous cervical lymphadenopathy. J Comput Assist Tomogr 1999;23:244-247.

13. Engin G, Acunas B, Acunas G, Tunaci M. Imaging of extrapulmonary tuberculosis. Radiographics 2000;20:471-488.

14. Geldmacher H, Taube C, Kroeger C, Magnussen H, Kirsten DK. Assessment of lymph node tuberculosis in northern Germany: a clinical review. Chest 2002;121:1177-1182. 
15. Polesky A, Grove W, Bnhatia G. Peripheral tuberculous lymphadenitis: epidemiology, diagnosis, treatment, and outcome. Medicine (Baltimore) 2005;84:350-362.

16. Yang Z, Kong Y, Wilson F, Foxman B, Fowler AH, Marrs CF, et al. Identication of risk factors for extrapulmonary tuberculosis. Clin Infect Dis 2004;38:199-205.

\section{ABOUT THE AUTHORS}

\section{Ramandeep Singh Virk (Corresponding Author)}

Assistant Professor, Department of ENT, Postgraduate Institute of Medical Education and Research, Chandigarh, India, Phone: 01722756760 e-mail: virkdoc@hotmail.com

\section{Darwin Kaushal}

Senior Resident, Department of ENT, Postgraduate Institute of Medical Education and Research, Chandigarh, India

\section{Ravi Sankar}

Senior Resident, Department of ENT, Postgraduate Institute of Medical Education and Research, Chandigarh, India

\section{Amit Babel}

Junior Resident, Department of ENT, Postgraduate Institute of Medical Education and Research, Chandigarh, India 